\title{
Health Care Consequences of Hospitalization with Clostrioides Difficile Infection: A Propensity Score Matching Study
}

\section{Bruce E. Hirsch}

Northwell Health

Myia S. Williams ( $\square$ mwilliam26@northwell.edu )

Northwell Health

Martin L. Lesser

The Feinstein Institutes of Medical Research

\section{Karalyn Pappas}

The Feinstein Institutes for Medical Research

\section{Dimitre G. Stefanov}

The Feinstein Institutes for Medical Research

\section{Thomas Iglio}

Northwell Health

\section{Craig Gordon}

Northwell Health

Renee Pekmezaris

Northwell Health

\section{Research Article}

Keywords: Clostridioides difficile infection, hospitalizations, SPARCS, mortality

Posted Date: October 8th, 2021

DOI: https://doi.org/10.21203/rs.3.rs-916667/v1

License: (1) (1) This work is licensed under a Creative Commons Attribution 4.0 International License. Read Full License 


\section{Abstract}

Background: Clostridiodies difficile infection (CDI) has been characterized by the Center for Disease Control and Prevention (CDC) as an urgent public health threat and a major concern in hospital, outpatient and extended-care facilities worldwide.

Methods: A retrospective cohort study of patients aged $\geq 18$ hospitalized with CDI in New York State (NYS) between January 1, 2014-December 31, 2016. Data were extracted from NY Statewide Planning and Research Cooperative (SPARCS) and propensity score matching was performed to achieve comparability of the CDI (case) and non-CDI (control) groups. Of the 3,714,486 hospitalizations, 28,874 incidence CDI cases were successfully matched to 28,874 controls.

Results: The matched pairs comparison demonstrated that CDI cases were more likely to be readmitted to the hospital at 30 (28.2625.53\% vs. $19.4618 .55 \%), 60$ (37.65\% 34.01\% vs. $26.0225 .18 \%), 90$ (42.9338.79\% vs. $30.4329 .70 \%)$ and 120 days ( $46.47 \% 41.99 \%$ vs. $33.7432 .93 \%)$, had greater mortality rates at 7 (3.68 $11.18 \%$ vs. $2.015 .15 \%)$ and 180 days (20.5426.56\% vs. $11.9614 .82 \%)$, with significant increases in length of stay and total hospital charges ( $p<0.001$, respectively).

Conclusions: CDI is associated with a large burden on patients and health care systems, significantly increasing hospital utilization, costs and mortality.

\section{Introduction}

Clostridiodies difficile infection (CDI) has been characterized by the Center for Disease Control and Prevention (CDC) as an urgent public health threat(1) and a major concern in hospital, outpatient and extended-care facilities worldwide.(2-4) The public health impacts of CDI are significant, with recent studies reporting annual healthcare costs to be as much as $\$ 4.8$ billion for acute care facilities alone and a great deal of variation in "extra" length of stay (LOS) and associated costs. $(4,5)$ A 2015 review of CDI outcomes demonstrated that, depending on the time frame- during endemic or epidemic periods of CDI, all-cause mortality and attributable mortality ranged from $11.8-38 \%$, and $0-16.7 \%$ respectively. $(6,7)$ The burden of annual CDI incident infections in the US is estimated to be 453,000 , cases per year, with increased incidence noted in those older than 65 years .(8-10) About $24 \%$ of cases were reported to occur in hospital settings, highlighting the need for prevention of CDI.(11) The issue of recurring CDI is also of concern, with recurrence rates varying from $5-50 \%$, with an average of $20 \% .(8,12)$ Lessa and colleagues(8) estimated that about 83,000 first recurrent infections occur between 14 and 56 days after the initial episode. Such numbers are alarming, given the risk of transmission and challenges in treating recurrent infections. $(8,12)$

The purpose of our study was to investigate the impact of CDI upon LOS, rehospitalization, mortality, and costs in patients hospitalized throughout New York State (NYS). We queried a large comprehensive, statewide database to assess the extent to which CDI patients have higher rehospitalization rates, greater health care expenditures and mortality than matched controls without CDI. Gaining a better 
understanding of the extended natural history of CDI may inform the need for interventions to enhance clinical outcomes and public health.

\section{Methods}

Data Sources. A retrospective cohort study of patients hospitalized in NYS was conducted. The Feinstein Institutes of Medical Research Institutional Review Board deemed that the study did not meet the definition of human subjects research; therefore, IRB review was not needed. Data were extracted from the New York Statewide Planning and Research Cooperative (SPARCS), and cross referenced by investigators with death data from Vital Statistics of New York State, to identify deaths that occurred after hospital discharge. All protocol methods and use of this data were carried out in accordance with relevant guidelines and regulations.

SPARCS is a comprehensive all payer data reporting system created in 1979 to collect information on hospital discharges from all Article 28 facilities operating in NYS. SPARCS is one of the largest data systems in the country, with over 2.3 million annual inpatient discharges and 6.7 million treat and release (i.e., same day) emergency room visits. (13) SPARCS currently collects patient level detail on patient characteristics, diagnoses and treatments, services, and charges for each hospital inpatient stay and outpatient visit. Death data were accessed from the New York State Vital Statistics Program, which registers live births, deaths, fetal deaths, induced terminations of pregnancy/abortions, etc.

Study Population and Selection Criteria. All patients aged $\geq 18$ years hospitalized between January 1 , 2014-December 31, 2016 were included in the analysis. A known CDI case was defined as one of ICD-9 and ICD-10 principal diagnostic codes: 00845, A0472, and A047. There were 3,714,486 total hospital discharges in NYS that met the eligibility criteria during the 2-year interval, of which 28,897 had a de novo CDI diagnosis (accounting for $0.78 \%$ of all discharges) and $3,685,589$ did not. The total sample of $3,714,486$ was a result of removing 23 hospital discharges (of which one was a CDI diagnosis) due to missing gender. Final propensity score matching (PSM) was 28,874 incident CDI cases successfully matched to 28,874 controls.

Exposure of Interest. The exposure of interest was diagnosis of CDI during hospitalization as documented in the medical chart. The data set was comprised of discharges between 01/01/14$12 / 31 / 16$, the primary period of analysis corresponded to $07 / 01 / 2014-06 / 30 / 2016$. There was a 6 month look back period (01/01/2014-06/30/2014) to determine whether a diagnosis of CDI in the analysis period was de novo (incident case) or a recurrent case. A 6 month follow up period (07/01/2016$12 / 31 / 2016)$ served to determine whether an exposed or control subject had any subsequent hospitalizations. A de novo CDI case was defined as a case of CDI in period of analysis, provided that there was no CDI visit for that patient in in the look back period, to avoid capture of recurrent infection. Controls were defined as all visits from subjects that never had a CDI diagnosis. Cases and controls who died in the hospital during the first visit were excluded from the analysis. In the event that a case or 
control died on the second or subsequent hospital visit, all data prior to that visit were included from the analysis.

Variables. Age, race, comorbidities (Charlson comorbidity index), insurance status, gender, ethnicity, 30,60, $90,120,180$ days readmission, mortality within $7,15,30,180$ and 360 days of discharge, hospital LOS and the total charges.

Outcomes. The primary outcome in this study was 30-day readmission. Secondary outcomes included $60,90,120,180$ days readmissions, mortality within $7,15,30,180$ and 360 days of discharge, hospital LOS and total charges.

Propensity Score Matching (PSM). In this retrospective cohort study, comparability of the CDI (case) and non-CDI (control) groups regarding potential confounding variables. This was accomplished using PSM. Variables to compute the propensity score for each patient were: age, gender, Charlson Comorbidity Index (CCl), race, ethnicity, insurance type, and month/year of admission. PSM was accomplished using greedy nearest neighbor 1:1 matching based on logit (PS) with a caliper of 0.05 , with an exact matching on month/year of admission.

Statistical Analyses. There were a total of 3,714,486 hospitalizations in New York State that met the eligibility criteria in the 2 year interval between $7 / 1 / 14$ and $6 / 30 / 16$, of which 28,897 were identified as having CDI. Of these, 28,874 incident CDI cases were successfully matched to 28,874 controls. Hospitalization that met eligibility critreria were identified and incident CDI cases determined. All cases, with the exception of the 23 instances of incomplete date, were successfully matched. The maximum standardized difference as percentage was 1.7\% (Table 2), which is below the suggested upper limit of $10 \%(14,15)$, and indicated a good balance between the matched groups. The variance ratios between the $\mathrm{CDI}$ and the pure control groups were between 1 and 1.03 for all variables in the matched observations, which is within the recommended range of 0.5 to 2 .(16) 
Table 2

Baseline Characteristics of the Incident CDI and Control groups in the Propensity Score Matched Sample

\begin{tabular}{|c|c|c|c|c|}
\hline Variable & $\begin{array}{l}\text { Incidence CDI cases } \\
\mathrm{N}=28,874\end{array}$ & $\begin{array}{l}\text { Controls } \\
\mathrm{N}=28,874\end{array}$ & $\begin{array}{l}\text { Standardized } \\
\text { difference in } \\
\% \text { s \# }\end{array}$ & $\begin{array}{l}\text { Variance } \\
\text { Ratio }\end{array}$ \\
\hline Age & $\begin{array}{l}67.55 \pm 17.73 \text { [median } \\
70(57-81)]\end{array}$ & $\begin{array}{l}67.67 \pm 17.63 \text { [median } \\
70(57-81)]\end{array}$ & -0.626 & 1.01 \\
\hline Female sex & $57.42 \%$ & $57.34 \%$ & 0.168 & 1.00 \\
\hline \multicolumn{5}{|l|}{ Race } \\
\hline White & $68.94 \%$ & $69.17 \%$ & -0.493 & 1.00 \\
\hline Black & $13.92 \%$ & $13.71 \%$ & 0.573 & 1.01 \\
\hline Other & $17.12 \%$ & $17.14 \%$ & 0.061 & 1.00 \\
\hline $\begin{array}{l}\text { Ethnicity_class } \\
\text { Hispanic / Other }\end{array}$ & $11.51 \%$ & $11.38 \%$ & 0.362 & 1.01 \\
\hline \multicolumn{5}{|l|}{ Insurance_status } \\
\hline Private / Other & $20.62 \%$ & $20.60 \%$ & 0.056 & 1.00 \\
\hline Medicare & $65.20 \%$ & $65.47 \%$ & -0.557 & 1.00 \\
\hline Medicaid & $14.18 \%$ & $13.93 \%$ & 0.618 & 1.01 \\
\hline $\begin{array}{l}\text { Total } \mathrm{CCl} \text { groups } \\
\text { per record } \star \star\end{array}$ & $\begin{array}{l}1.12 \pm 1.43 \text { [median } 0 \\
(0-2)]\end{array}$ & $\begin{array}{l}1.10 \pm 1.41 \text { [median } 0 \\
(0-2)]\end{array}$ & 1.707 & 1.03 \\
\hline
\end{tabular}

Baseline characteristics of the incident CDI and control groups were compared using chi-square and twosample t-tests, as appropriate (Table 1). Comparisons between the matched CDI and control groups were based on McNemar's test (mortality and the readmission indicators), paired t-test (Log (total charges)) and Wilcoxon signed rank test (LOS). All categorical data are reported as percentages. Continuous variables are reported as mean $\pm S D$ and median (25th, 75th percentiles). Summary statistics for the outcomes, with the $95 \%$ confidence intervals $(\mathrm{Cl})$ for the difference between the matched groups are presented (Table 3). A result was considered statistically significant at the $p<0.05$ level. All analyses were performed using SAS version 9.4 (SAS Institute Inc, Cary, NC). 
Table 1

Baseline Characteristics of the Incident CDI and Control groups

\begin{tabular}{|c|c|c|c|c|}
\hline Variable & $\begin{array}{l}\text { Incidence CDI cases } \\
\mathrm{N}=\mathbf{2 8 , 8 9 7}\end{array}$ & $\begin{array}{l}\text { Controls } \\
\mathrm{N}=3,685,589\end{array}$ & $\begin{array}{l}\text { Standardized } \\
\text { difference in } \\
\% \text { s \# }\end{array}$ & $\begin{array}{l}\mathrm{p}- \\
\text { value* }\end{array}$ \\
\hline Age & $\begin{array}{l}67.55 \pm 17.72[\text { median } \\
70(57-81)]\end{array}$ & $\begin{array}{l}56.69 \pm 20.79[\text { median } \\
58(38-73)]\end{array}$ & 56.182 & $<.001$ \\
\hline Female sex & $57.41 \%$ & $57.59 \%$ & -0.365 & 0.5365 \\
\hline Race & & & & $<.001$ \\
\hline White & $68.91 \%$ & $58.88 \%$ & 21.012 & \\
\hline Black & $13.93 \%$ & $18.65 \%$ & -12.833 & \\
\hline Other & $17.16 \%$ & $22.47 \%$ & -13.345 & \\
\hline $\begin{array}{l}\text { Ethnicity_class } \\
\text { Hispanic / Other }\end{array}$ & $11.52 \%$ & $16.18 \%$ & -13.499 & $<.001$ \\
\hline Insurance_status & & & & $<.001$ \\
\hline Private / Other & $20.61 \%$ & $31.58 \%$ & -25.184 & \\
\hline Medicare & $65.19 \%$ & $41.95 \%$ & 47.919 & \\
\hline Medicaid & $14.20 \%$ & $26.46 \%$ & -30.842 & \\
\hline $\begin{array}{l}\text { Total CCl groups per } \\
\text { record ** }\end{array}$ & $\begin{array}{l}1.12 \pm 1.43 \text { [median } 0 \\
(0-2)]\end{array}$ & $\begin{array}{l}0.74 \pm 1.20 \text { [median } 0 \\
(0-1)]\end{array}$ & 29.239 & $<.001$ \\
\hline \multicolumn{5}{|c|}{ *P-values based on the Chi-square and the two-sample t-tests. } \\
\hline \multicolumn{5}{|c|}{$\begin{array}{l}\text { \# The standardized difference in } \% \text { is the mean difference as a percentage of the average standard } \\
\text { deviation. }\end{array}$} \\
\hline \multicolumn{5}{|c|}{$\begin{array}{l}\text { All categorical data are reported as percentages. The } 2 \text { continuous variables, Age and Total CCI } \\
\text { groups per record are reported as mean } \pm S D \text { and median ( } 25 \text { th, } 75 \text { th percentiles). }\end{array}$} \\
\hline
\end{tabular}


Table 3

Analysis of the Primary and the Secondary Outcomes

\begin{tabular}{|c|c|c|c|c|}
\hline Outcome & $\begin{array}{l}\text { Incidence CDI } \\
\text { cases }\end{array}$ & Control & Diff $(95 \% \mathrm{Cl})$ & $\begin{array}{l}\text { p- } \\
\text { value* }\end{array}$ \\
\hline $30 \mathrm{~d}$ Readmission $(\mathrm{n}=$ & \multirow[t]{2}{*}{$28.26 \%$} & \multirow[t]{2}{*}{$19.46 \%$} & \multirow{2}{*}{$\begin{array}{l}8.81(8.11- \\
9.5)\end{array}$} & \multirow[t]{2}{*}{$<.0001$} \\
\hline 28,846 pairs) & & & & \\
\hline $60 \mathrm{~d}$ Readmission ( $\mathrm{n}=28,846$ pairs) & $37.65 \%$ & $26.02 \%$ & $\begin{array}{l}11.62(10.87- \\
12.38)\end{array}$ & $<.0001$ \\
\hline $90 \mathrm{~d}$ Readmission ( $\mathrm{n}=28,846$ pairs) & $42.93 \%$ & $30.43 \%$ & $\begin{array}{l}12.5(11.72- \\
13.28)\end{array}$ & $<.0001$ \\
\hline $120 \mathrm{~d}$ Readmission ( $\mathrm{n}=28,846$ pairs) & $46.47 \%$ & $33.74 \%$ & $\begin{array}{l}12.73(11.94- \\
13.52)\end{array}$ & $<.0001$ \\
\hline $180 \mathrm{~d}$ Readmission ( $\mathrm{n}=28,846$ pairs) & $51.39 \%$ & $38.76 \%$ & $\begin{array}{l}12.63(11.82- \\
13.43)\end{array}$ & $<.0001$ \\
\hline $\begin{array}{l}\text { Mortality within } 7 \text { days of discharge } \\
(\mathrm{n}=28,874 \text { pairs })\end{array}$ & $3.68 \%$ & $2.01 \%$ & $\begin{array}{l}1.67(1.4- \\
1.94)\end{array}$ & $<.0001$ \\
\hline $\begin{array}{l}\text { Mortality within } 15 \text { days of discharge } \\
\text { ( } n=28,874 \text { pairs })\end{array}$ & $5.76 \%$ & $3.17 \%$ & $\begin{array}{l}2.59(2.26- \\
2.93)\end{array}$ & $<.0001$ \\
\hline $\begin{array}{l}\text { Mortality within } 30 \text { days of discharge } \\
(n=28,874 \text { pairs })\end{array}$ & $8.65 \%$ & $4.71 \%$ & $\begin{array}{l}3.93(3.53- \\
4.34)\end{array}$ & $<.0001$ \\
\hline $\begin{array}{l}\text { Mortality within } 180 \text { days of } \\
\text { discharge }\end{array}$ & $20.54 \%$ & $11.96 \%$ & $\begin{array}{l}8.58(7.98- \\
9.17)\end{array}$ & $<.0001$ \\
\hline \multicolumn{5}{|l|}{$(n=28,874$ pairs $)$} \\
\hline $\begin{array}{l}\text { Mortality within } 360 \text { days of } \\
\text { discharge }\end{array}$ & $26.15 \%$ & $16.55 \%$ & $\begin{array}{l}9.6(8.93- \\
10.26)\end{array}$ & $<.0001$ \\
\hline \multicolumn{5}{|l|}{$(n=28,874$ pairs $)$} \\
\hline $\begin{array}{l}\text { LOS in days-Median (25-75th Perc.) } \\
(n=28,874 \text { pairs })\end{array}$ & $9(5-16)$ & $4(2-7)$ & $4(0-11)$ & $<.0001$ \\
\hline $\begin{array}{l}\text { Total Charges }(\$) \text { - Geometric mean } \\
(95 \% \mathrm{Cl})\end{array}$ & $\begin{array}{l}58,430(57,689- \\
59,181)\end{array}$ & $\begin{array}{l}31,705(31,363- \\
32,051)\end{array}$ & $\begin{array}{l}1.84(1.81- \\
1.87)\end{array}$ & \\
\hline
\end{tabular}

\section{Results}

There were a total of 3,808,146 hospitalizations in NYS in the 2 year interval 7/1/14 - 6/30/16with 31,998 cases identified as having CDI (accounting for $0.84 \%$ of all admissions). 
Readmission. Matched pairs comparison of the 28,874 incident CDI cases to 28,874 controls demonstrated that CDI cases were more likely to be readmitted to the hospital at all time points assessed. Hospital readmission rate at 30 days was $28.26 \%$ for CDI cases versus $19.46 \%$ for controls $(p<.0001$, absolute difference $=8.81 \%$, Table 3 ). Similarly, the hospital readmission rate at 60 days was $37.65 \%$ for CDI cases, versus $26.02 \%$ for controls $(p<.0001$, absolute difference $=11.62 \%)$. The hospital readmission rate at 90 days was $42.93 \%$ for $\mathrm{CDI}$ cases, versus $30.43 \%$ for controls $(p<.0001$, absolute difference $=$ $12.50 \%$ ). The hospital readmission rate at 120 days was $46.47 \%$ for $C D I$ cases versus $33.74 \%$ for controls $(p<.0001$, absolute difference $=12.73 \%)$. Finally, the hospital readmission rate at 180 days was $51.39 \%$ for $\mathrm{CDI}$ cases versus $38.76 \%$ for controls ( $p<.0001$, absolute difference $=12.63 \%$ ).

Mortality. We found greater mortality rates in CDI cases at all time follow up intervals (Table 3). The mortality rate at 7 days was $3.68 \%$ for CDI cases versus $2.01 \%$ for controls ( $p<.0001,1.8$-fold increase, absolute difference $=1.67 \%$ ). The mortality rate at 180 days was $20.54 \%$ for CDI cases versus $11.96 \%$ for controls $(p<.0001,1.72$-fold increase, absolute difference $=8.58 \%)$.

Length of Stay. LOS was significantly longer $(p<0.0001)$ in the CDI matched group. We used the Wilcoxon signed rank test to compare the distribution of this outcome in the two groups, due to its skewness. Median LOS in days (25-75th percentile) were 9 (5-16) and 4 (2-7) for the CDI and controls matched groups (Table 3).

Total Charges. Hospital charges were significantly greater in CDI cases $(p<0.0001)$. The median $(25-75$ th percentile) hospital charges were $\$ 55,171(\$ 26,753-\$ 119,933)$ and $\$ 30,811(\$ 16,693-\$ 57,838)$ (Table3) for the $\mathrm{CDI}$ and controls matched groups, respectively, an increase of an additional $\$ 24,360$. We compared total charges after log transformation, due to the skewed distribution of this outcome. The geometric mean $(95 \% \mathrm{Cl})$ for the total charges were estimated to be $\$ 58,430(\$ 57,689-\$ 59,181)$ and $\$ 31,705(\$ 31,363-\$ 32,051)$ in the CDI and control groups, respectively. On average, the total charges in the $\mathrm{CDI}$ group were 1.84 times $(95 \% \mathrm{Cl}: 1.81$ to $1.87, \mathrm{p}<0.0001)$ larger than the matched control group.

\section{Discussion}

Although a number of studies have investigated the impact of $\mathrm{CDI}$, there has been a dearth of large-scale investigations that have statistically accounted for important confounding variables such as severity of illness, age, and insurance status. Our study was able to match 28,874 incident CDI cases to 28,874 controls, accounting for important confounding variables to give us a comprehensive understanding of the impact of CDI. The objective of our study was to investigate the impact of de novo CDI in hospitalized patients upon re-hospitalization, costs and mortality in NYS.

In our PSM study, utilizing the NYS SPARCS database of hospitalizations cross referenced with mortality data from Vital Statistics of New York State, it is not surprising that we found that hospitalization for CDI is common, occurring in 28,897 discharges during the 2 -year period (7/1/14 and 6/30/16), accounting for $0.78 \%$ of all hospitalizations. 
When compared with controls, our data found that rates of hospitalization were greater for CDI patients at $30,60,90$ and 120 days. The absolute difference is maintained through these periods, suggesting a constitutional predisposition in CDI patients. If readmission were due solely to recurrent CDI, one would expect the greatest differences to occur earliest, when the risk of CDI recurrence is greater. Interestingly, a previous study utilizing a similar methodology in 2015 found a 19\% attributable readmission rate within 180 days in patients with $\mathrm{CDI}(6)$; our hospital readmission rate at 180 days was found to be much higher: $51.39 \%$ for CDI cases.

Our data also indicates greater mortality rates in CDI cases at all time intervals compared to controls: at $7,15,30,180$, and 360 days of discharge $(p<0.0001$.) This enhanced mortality rate was also sustained through all examined follow up intervals.

Greater utilization of health care resources was documented in CDI cases as well: in terms of costs, our study found significantly attributable costs of total charges of $\$ 26,753-\$ 119,933$ compared to one study in which the authors report reported CDI-attributable costs ranging from $\$ 3427$ to $\$ 9960$ in hospitalized patients during a similar time period (2015).(6) In NYS alone, we found these inpatient charges approached a billion dollars during the two-year study period.

It may well be that the CDI is a marker of vulnerability, as enhanced mortality and need for additional health care resources experienced by patients hospitalized with CDI are maintained throughout the follow up period.

In a previous study, re-hospitalization rates within 90 days, specifically for severe sepsis showed markedly increases when original hospitalization was associated with events resulting in dysbiosis. When compared to patients with infections, patients with CDI experienced 16.8\% 90-day readmission for severe sepsis, these conditions are associated with marked perturbation of the gut microbiome and were compared to cases without identified infection who experienced 3.7\% 90-day readmission for severe sepsis. These figures are comparable with the hospital readmission rate at 90 days for all causes in this current study which was $38.78 \%$ for CDI cases and $29.70 \%$ for controls. We speculate that dysbiosis is a significant and reversible factor explaining ongoing enhanced rehospitalization and mortality in CDI cases.

This comprehensive evaluation confirms previous work describing enhanced rehospitalization rates. This study contributes quantification of the enhanced readmission rate, mortality rate and cost of care with prolonged follow up. We find that CDI is associated with an increased length of stay of 5 days and an additional $\$ 27,891$ in hospital charges. Our data indicates an increase in readmission rates of approximately $30 \%$ at $30,60,90$ and 120 days follow-up. We were surprised to note that hospitalization with CDI was associated with a doubling of mortality through 30 days, with a sustained increased risk, which only modestly decreased at 360 days. Our finding that hospitalization with CDI is a marker for adverse outcomes sustained through 360 days expands knowledge of the epidemiology of CDI and facilitates computation of benefits of interventions. 
Our study has several limitations. The New York State SPARCS system is a robust database, but it is not without limitations. The database is updated monthly and is usually considered "complete" around midAugust of the subsequent year. Incomplete SPARCS data are available on a one-month lag. Thus, incomplete February 2014 data are available in March 2014 and complete February 2014 data are available in August 2015. Because data are reconciled gradually, incomplete data that is delivered later in the subsequent year will be more complete than if supplied early on. Thus, incomplete February 2014 data that is delivered in June will be more complete than if delivered in March.

To ensure as complete a data set as possible, we applied to the Data Governance Committee (DGC) of New York State (responsible for reviewing SPARCS identifiable data requests) in late 2017 and received the data in 2018. Despite our best efforts to ensure a complete data set, possible limitations of the data include accuracy of diagnosis (likely underreporting of CDI), and the fact that we did not match for clinical conditions or diagnoses. We chose not to match on clinical diagnostic variables given the statistical power provided by our large cohort. This decision was supported by our ability to successfully match 28,874 incident CDI cases to 28,874 controls (comparison cohort).

The increased hospital readmission rate, mortality and health care costs associated with hospitalization for $\mathrm{CDI}$ poses a significant public health challenge. The gut microbiome represents a therapeutic target for patients with CDI.(17-19) Effective strategies such as stewardship of antibiotics and conservatorship of the gut microbiome to restore patients to long term health require continued investigation.

\section{Declarations}

Ethics approval and consent to participate: The Feinstein Institutes of Medical Research Institutional Review Board deemed that the study did not meet the definition of human subjects research; therefore, IRB review was not needed. Consent for participation was also not needed. All protocol methods and use of this data were carried out in accordance with relevant guidelines and regulations.

Consent for publication: Not applicable

Availability of data and materials: The data that support the findings of this study are available from New York State Department of Health (NYSDOH) but restrictions apply to the availability of these data, which were used under license for the current study, and so are not publicly available. Data are however available from the New York State Department of Health subject to their Data Protection Review Board.

Competing interests: All authors have no conflict of interests to report.

Funding: Karin and Dayton Brown Division of Infectious Diseases, Northwell Health

Author Contributions: BEH, MSW, MLL and RK conceptualized the study. MLL, KP, DG, TI and CG were responsible for data curation. MLL, KP and DGS did the formal analysis. BEH, MSW and RP did the investigation. BEH, MSW, MLL, KP, TI, CG and RP developed the methodology. BEH, and MSW were responsible for project administration. $\mathrm{BEH}, \mathrm{MLL}, \mathrm{TI}, \mathrm{CG}$ provided resources to run data analysis and 
complete the project. BEH, MLL and RP provided project supervision. MLL, KP, DGS, TI, CG provided validation. MLL, DSG, TI, CG provided visualization of the data. BEH, MSW, MLL, DSG and RP were involved in the original draft preparation. $B E H, M S W, M L L, K P, D S G, T I, C G$, and RP were all involved in the writing -review and editing.All authors have contributed in the manuscript revision and read and approved the final version for publication.

\section{Acknowledgements: NA}

\section{References}

1. Prevention $C$ for $D C$ and. Biggest Threats and Data | Antibiotic/Antimicrobial Resistance I CDC [Internet]. [cited 2020 Aug 3]. Available from: https://www.cdc.gov/drugresistance/biggestthreats.html

2. Guh AY, Kutty PK. Clostridioides difficile infection [Internet]. Vol. 169, Annals of Internal Medicine. American College of Physicians; 2018 [cited 2020 Aug 3]. p. ITC49-62. Available from: https://pubmed.ncbi.nlm.nih.gov/30285209/

3. Marra AR, Perencevich EN, Nelson RE, Samore M, Khader K, Chiang HY, et al. Incidence and Outcomes Associated With Clostridium difficile Infections: A Systematic Review and Meta-analysis. JAMA Netw open [Internet]. 2020 Jan 3 [cited 2020 Aug 3];3(1):e1917597. Available from: https://jamanetwork.com/

4. Bouza E. Consequences of Clostridium difficile infection: Understanding the healthcare burden [Internet]. Vol. 18, Clinical Microbiology and Infection. Blackwell Publishing Ltd; 2012 [cited 2020 Aug 3]. p. 5-12. Available from: https://pubmed.ncbi.nlm.nih.gov/23121549/

5. Wilkins T, Sequoia J, Jennings W, Dorn B. Probiotics for Gastrointestinal Conditions: A Summary of the Evidence [Internet]. Vol. 96. 2017 [cited 2020 Aug 3]. Available from: .

6. Kwon J, Olsen M, Dubberke E. The morbidity, mortality, and costs associated with Clostridium difficile infection. Infect Dis Clin North Am. 2015;29(1):123-134.

7. Olsen MA, Stwalley D, Demont C, Dubberke ER. Clostridium difficile infection increases acute and chronic morbidity and mortality. Infect Control Hosp Epidemiol. 2019;40(1):65-71.

8. Lessa FC, Mu Y, Bamberg WM, Beldavs ZG, Dumyati GK, Dunn JR, et al. Burden of Clostridium difficile infection in the United States. N Engl J Med [Internet]. 2015 Feb 26 [cited 2020 Aug 3];372(9):825-34. Available from: http://www.nejm.org/doi/10.1056/NEJMoa1408913

9. Roos R. CDC puts $C$ difficile burden at 453,000 cases, 29,000 deaths I CIDRAP [Internet]. Center for Infectious Disease Research and Policy (CIDRAP). 2015 [cited 2020 Aug 3]. Available from: https://www.cidrap.umn.edu/news-perspective/2015/02/cdc-puts-c-difficile-burden-453000-cases29000-deaths

10. CDC. Nearly half a million Americans suffered from Clostridium difficile infections in a single year I CDC Online Newsroom I CDC [Internet]. CDC. 2015 [cited 2020 Aug 3]. Available from:

https://www.cdc.gov/media/releases/2015/p0225-clostridium-difficile.html 
11. Gould C V., File TM, McDonald LC. Causes, burden, and prevention of Clostridium difficile infection [Internet]. Vol. 23, Infectious Diseases in Clinical Practice. Lippincott Williams and Wilkins; 2015 [cited 2020 Aug 3]. p. 281-8. Available from: /pmc/articles/PMC6488933/?report=abstract

12. Hopkins RJ, Wilson RB. Treatment of recurrent Clostridium difficile colitis: a narrative review. Gastroenterol Rep [Internet]. 2018 [cited 2020 Aug 3];6(1):21. Available from: /pmc/articles/PMC5806400/? report=abstract

13. Office of Quality and Patient Safety. New York State Report on Quality, Patient Safety, and Efficiency Division of Information and Statistics [Internet]. 2016 [cited 2020 Aug 12]. Available from: http://www.health.ny.gov/statistics/sparcs/.

14. Normand SLT, Landrum MB, Guadagnoli E, Ayanian JZ, Ryan TJ, Cleary PD, et al. Validating recommendations for coronary angiography following acute myocardial infarction in the elderly: A matched analysis using propensity scores. J Clin Epidemiol [Internet]. 2001 [cited 2020 Aug 12];54(4):387-98. Available from: https://pubmed.ncbi.nlm.nih.gov/11297888/

15. Austin PC. Balance diagnostics for comparing the distribution of baseline covariates between treatment groups in propensity-score matched samples. Stat Med [Internet]. 2009 Nov 10 [cited 2020 Aug 12];28(25):3083-107. Available from: https://pubmed.ncbi.nlm.nih.gov/19757444/

16. Rubin DB. Using propensity scores to help design observational studies: Application to the tobacco litigation. Heal Serv Outcomes Res Methodol [Internet]. 2001 [cited 2020 Aug 12];2(3-4):169-88. Available from: https://link.springer.com/article/10.1023/A:1020363010465

17. Tilg H, Kaser A. Gut microbiome, obesity, and metabolic dysfunction [Internet]. Vol. 121, Journal of Clinical Investigation. J Clin Invest; 2011 [cited 2020 Aug 3]. p. 2126-32. Available from: https://pubmed.ncbi.nlm.nih.gov/21633181/

18. Hirsch BE, Saraiya N, Poeth K, Schwartz RM, Epstein ME, Honig G. Effectiveness of fecal-derived microbiota transfer using orally administered capsules for recurrent Clostridium difficile infection. BMC Infect Dis [Internet]. 2015 Apr 17 [cited 2020 Aug 3];15(1):191. Available from: https://bmcinfectdis.biomedcentral.com/articles/10.1186/s12879-015-0930-z

19. Li Q, Wang C, Tang C, He Q, Zhao X, Li N, et al. Therapeutic modulation and reestablishment of the intestinal Microbiota with fecal Microbiota transplantation resolves sepsis and diarrhea in a patient [Internet]. Vol. 109, American Journal of Gastroenterology. Nature Publishing Group; 2014 [cited 2020 Aug 3]. p. 1832-4. Available from: https://pubmed.ncbi.nlm.nih.gov/25373588/ 